\title{
FIVE YEAR EVALUATION OF THE STUDENT DIVERSITY PROGRAM: A RETROSPECTIVE QUASI-EXPERIMENT
}

\author{
VERNON R. PADGETT
}

JOHN F. REID, JR.

California State University, Fullerton

\begin{abstract}
The Student Diversity Program (SDP) initially delivered academic and social support to Black student athletes, but expanded to include a more diverse group of students at risk of disqualification. To assess whether this program increased retention, we examined graduation rates and ending GPAs of students in four SDP cohorts from 1994 and $1995(n=39)$, comparing them to matched students who were not in the program $(n=434)$, over five years of academic progress. We matched these comparison students on semester of enrollment in CSUF, ethnic group, sex, age, transfer status (FTF or Transfer), and cumulative GPA at the end of their first semester. SDP students graduated at twice the rate of the comparable students after five years. SDP student's GPA of last record was not however different from that of comparison students. It appears that the Student Diversity Program achieves its goal of delivering academic support, and is effective not only with Black athletes but with a more diverse group of at-risk students as well.
\end{abstract}

\section{INTRODUCTION}

The Mission of the Student Diversity Program (SDP) at Cal State Fullerton is to address the low retention and graduation rates of "at-risk" (at risk of academic disqualification) students by improving their use of campus academic support services, and to enhance student academic development and achievement by providing additional support services tailored to meet students' individual needs. 
The SDP began in Summer 1998 after the success of its predecessors, the Black Ombudsman Program (Reid, 1996), which began in 1993, and the Teaching Ombudsman Action Program, which began in 1996. The Student Diversity Program support network, building on the earlier programs, is a multilevel retention program for at risk students. Most of the students in the earlier program cohorts were Black athletes, but later years were characterized by increased ethnic diversity as the program reached out to a broader student base, including non-Blacks and non-athletes. Graduation rates for Black athletes at Cal State Fullerton had been dismal previous to the program. Only three Black basketball players had graduated in the 12 years preceding inauguration of the Black Ombudsman Program. For comparison, the graduation rate is 40.8 percent for nine years across public four-year universities (Peltier, Laden, \& Matranga, 1999, p. 358).

The SDP is a large program, and it appears to meet its goals: enrollment of at-risk students doubled from 1997-1998 to 1998-1999, to 361 students, and 93 percent of SDP participants enrolled in the Fall 1998 term were enrolled through the Fall 1999 term (unless they graduated). Fall 2000 SDP student enrollment has soared to 1200 . Cost of program in the previous semester was $\$ 47$ per student, compared to more than $\$ 700$ for the other major student support service program (calculated as total O\&E funds budgeted divided by number of active student participants).

\section{Other Student Support Available}

Our campus provides a range of student academic services, including academic tutoring. The campus recently opened a Learning Assistance Center; EOP has provided academic counseling and referrals for many years; our Fullerton First Year program provides a large number of services to selected first time freshmen; and the Dean of Students has a variety of student support programs. Thus, the SDP is one of many programs available to CSUF students.

\section{Goals of SDP}

The first goal in the Student Diversity Program has been to provide guidance and retention services to diverse student populations by developing action plans and programs to address academic, social, and cultural needs. The second SDP goal has been to maintain a complex early assessment and reporting system to integrate students into university life. These elements have been shown to correlate with personal and academic success (Ottens, Johnson, \& Green, 1996; Sedlacek, 1996; Tracey \& Sedlacek, 1987). Factors present in the SDP program are well represented in the set of Out-of-Class Validation Factors given in Holmes, Ebbers, Robinson, and Mugenda's (2000, p. 54) excellent review of variables contributing to the retention and graduation of African-American students. 


\section{Description of SDP}

Important strategies of the SDP include "catch-back" planning, psychological counseling, faculty mentoring, group counseling, peer mentoring, and multicultural training, all aimed at increasing self-efficacy, self-esteem, mastery, commitment, coping skills, and cultural awareness. The "catch-back" plan uses theories based on building self-esteem, self-efficacy, and mastery through the use of planning, assessment and expectation, and assertiveness training. Key instruments include the Time Management instrument, the Goal Setting Pyramid, and the Art of Mastery instrument (all are available from the second author). The model incorporating the Catch-Back plan and these instruments all aim at moving students' control locus from external to internal, improving academic integration, developing an "information rich" environment, and improving the campus climate for learning. Basic tenets of the SDP are found in Reid (1996, pp. 193-199). The SDP further provides participants with role models, mentors, and advisors via a corps of community leaders who work with the participants on a volunteer basis. The SDP Advisory Council, composed of faculty, staff, and a physician, provides a further communication and support network. Are all parts of the program effective? SDP staff address this concern by conducting evaluations of the program routinely, with staff as well as student participants rating all aspects of the program.

\section{What Program Evaluation Did We Perform}

Of the four types of Program Evaluation (Needs Assessment, Process Assessment, Outcomes Assessment, and Economic Efficiency Assessment or Cost/ Benefit Analysis), we conducted an outcome assessment. This outcome assessment served as a more formal evaluation following two briefer assessments in which SDP Interns provided both quantitative and narrative ratings. These briefer assessments revealed very positive overall evaluations.

\section{What is a "Quasi-Experiment"?}

Quasi-experiments attempt to approximate the control features of true experiments "to infer that a given treatment did have its intended effect" and are typically used in program evaluation research (Cozby, 1997, p. 163). This design is classed by Cook and Campbell (1979) as a Nonequivalent Control Group Design (p. 95).

\section{How to Measure Program Success?}

As noted earlier, persistence of SDP students exceeded 90 percent on a year-toyear basis, a far higher persistence rate than non-SDP students. Persistence did not seem a suitable dependent measure, however, as persistence data were not obtainable for the university as a whole, and even defining "persistence" precisely 
and to the satisfaction of all seemed beyond our means. We viewed GPA and graduation rates as "harder" measures, and ones we could obtain.

\section{Research Question and Strategy}

Does the Student Diversity Program meet its goals of improving student success? To evaluate the program, we calculated graduation rates and GPAs of students in four early cohorts of the program. We constructed a large comparison group as carefully as we could. We then compared the academic performance of SDP students, on those two measures, to the performance of similar students not in the program.

\section{METHOD}

\section{Participants and Design}

All SDP students from the first two years of the program were studied. There were nine students in the Spring 1994 SDP Cohort, 10 in Fall of 1994, five in Spring of 1995, and 16 in the Fall 1995 Cohort, for a total of 40 SDP students. Demographic characteristics of these students are given in Tables 1 through 5 . We eliminated one SDP student from the study because her program enrollment date preceded her university enrollment date (of Spring 1996), allowing her (and her comparison students) less than four years for graduation. Thus, a total of 39 SDP students were studied. The design was a retrospective quasi-experiment.

\begin{tabular}{lc}
$\begin{array}{l}\text { Table 1. Frequencies of SDP Students } \\
\text { by Ethnicity and Gender, } \\
\text { Spring }\end{array}$ 1994 Cohort \\
\hline Black males & 8 \\
White females & 1 \\
Total students & 9 \\
\hline
\end{tabular}

Table 2. Frequencies of SDP Students by Ethnicity and Gender, Fall 1994 Cohort

\begin{tabular}{lr}
\hline Black males & 9 \\
Black females & 1 \\
Total students & 10 \\
\hline
\end{tabular}




\begin{tabular}{|c|c|}
\hline & \\
\hline lack males & 2 \\
\hline lack females & 3 \\
\hline otal students & 5 \\
\hline
\end{tabular}

\begin{tabular}{lc}
$\begin{array}{c}\text { Table 4. Frequencies of SDP Students } \\
\text { by Ethnicity and Gender, } \\
\text { Fall } 1995 \text { Cohort }\end{array}$ \\
\hline \multicolumn{2}{c}{ Black (African American) males } \\
African male & 2 \\
Turkish male & 1 \\
African American females & 1 \\
Hispanic female & 8 \\
Anglo male & 1 \\
Asian female & 1 \\
Total students & 1 \\
\end{tabular}

\section{Procedure}

\section{Extraction from Student Records Database}

We extracted data from the CSUF Student Information System (SIS+), on 45 different criteria, on all students enrolled in the university each semester from Fall of 1990 through the following four years. These files included semesterby-semester academic performance through Fall of 1999 (or semester of last enrollment.)

\section{Creation of Comparison Groups}

We created comparison groups by matching each SDP student with a group of comparison students taken from the student records database, as follows. First, we selected all students who entered the university the same semester as the SDP student. This involved matching on eight different entering semesters, from Fall of 1990 to Fall of 1995. Next, we sorted the students in an Excel file for the appropriate entering semester, on gender, ethnicity, age, transfer status, and GPA at the end of the first semester of work (nested in that order). We then matched each SDP student with other students who: 


\begin{tabular}{lr}
$\begin{array}{l}\text { Table 5. Frequencies of SDP Students } \\
\text { by Ethnicity and Gender, } \\
\text { All 1994-1995 Cohorts }\end{array}$ \\
\hline African American males & 21 \\
African male & 1 \\
Turkish male & 1 \\
African American females & 12 \\
Hispanic female & 1 \\
Anglo-American females & 1 \\
Anglo-American male & 1 \\
Asian female & 1 \\
Total SDP students & 39 \\
\hline
\end{tabular}

- had enrolled in CSUF the same semester,

- were the same ethnic group,

- were the same sex,

- were within two years of the same age,

- were the same transfer status (FTF or Transfer),

- had the same approximate GPA after one semester at CSUF, and

- had enrolled in classes.

This provided a total of seven different matching criteria. For example, we matched one SDP member, a Black male First Time Freshman who entered in Fall of 1990, and was born in April 1972, with a group of students not in the SDP Program. These matching students were male, Black, within \pm 2 years of the SDP student's age, were also First Time (not Transfer) status, and were within 0.7 G.P.A. units on their GPA after one semester at the university. Each of the 39 students was matched with several non-SDP students. For a single Student Diversity Program member, there were from four to 54 matching students in separate comparison groups. The median number of students across comparison groups was 15. After the selection of comparable students, we removed any students who were also in the SDP program. Finally, these groups were combined and duplications removed.

Most of the members of the SDP were athletes. We were unable to match these students with non-SDP athletes, as nearly all the athletes meeting the matching criteria were already in the Student Diversity Program.

Next, we calculated the final cumulative GPAs and the percentage of students who had graduated in the comparison groups. Ethnicity and gender of the SDP students are shown by cohort in Tables 1 through 4, and combined in Table 5. 


\section{RESULTS}

\section{Spring 1994 SDP Cohort, $N=9$}

Of the students who started the SDP in Spring of 1994, five graduated, for a ratio of 5 of 9 , or 56 percent, at the time we evaluated the program, which was Spring 2000. The average GPA of last record for these SDP students was 2.11, sd $=.36$. In the comparison group of 95 students, 25 students graduated - a graduation rate of 26.3 percent. The GPA for this comparison group was $2.15, s d=.56$.

\section{Fall 1994 SDP Cohort, $N=10$}

For Students in the Fall 1994 SDP cohort, the graduation rate was 3 of 10, or 30 percent. In the comparison group, 25 students graduated. Those comparison students, $n=93$, had a graduation rate of 26.8 percent. The graduation rate for the SDP students was about the same as that of the comparison group. The final GPA for the SDP students was $2.53, s d=.41$. The GPA for the comparison group was $2.20, s d=.69$.

\section{Spring 1995 SDP Cohort, $N=5$}

For the Spring 1995 SDP cohort, the graduation rate was 2 of 5, or 40 percent. In the comparison group, 15 students graduated. The comparison group of 51 students had a graduation rate of 29.4 percent. Graduation rate for the SDP students was higher than that of the comparison group. The final GPA for the SDP students was $2.15, s d=.30$. The GPA for the comparison group was 2.48, $s d=.61$.

\section{Fall 1995 SDP Cohort, $N=15$}

For the Fall 1995 SDP cohort, the graduation rate was 8 of 15, or 53.3 percent. In the comparison group of 259 students, 52 students graduated. The comparison group had a graduation rate of 20.1 percent. Graduation rate for the SDP students was more than twice that of the comparison group. The final GPA for the SDP students was $2.46, s d=.27$, compared to a GPA in the comparison group of $2.30, s d=.57$.

\section{Combined SDP Cohorts}

The four comparison groups were combined and duplicate students deleted, leaving 434 comparison students. 


\section{Graduation Rates}

Overall graduation rate across SDP cohorts is 18 of 39 , or 46.2 percent. Overall graduation rate across the combined comparison groups is 102 of 434 or 23.5 percent. The graduation rate for students in the Student Diversity Program was twice that of students in the comparison group. Is the proportion of graduation statistically different among SDP students than among comparison students? The test statistic reveals a highly significant test difference, $\chi_{(1)}^{2}=9.70, p<.005$. Less than one time in 200 would we expect to find a difference of this magnitude in the proportion of graduation between these two groups, if the difference was due to chance (see Figure 1).

\section{GPA}

Grade point average of last record for the 39 SDP students was 2.36, $s d=37$, compared to the average GPA of $2.28, s d=.30$, across comparison student GPAs. This apparent difference was not statistically reliable by Matched Pairs $t(38)=1.29, p=.11$.

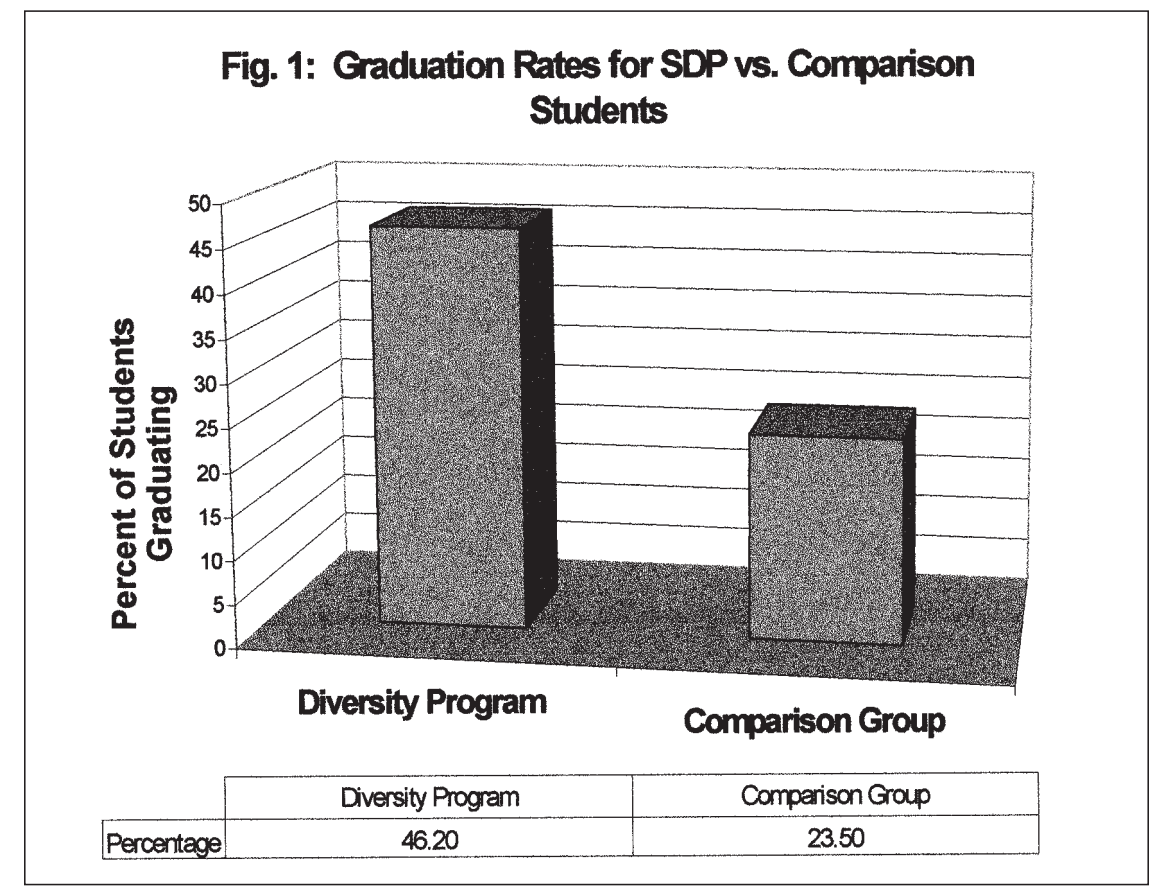

Figure 1. Graduation rates for student diversity program vs. comparison students. 


\section{DISCUSSION}

The 39 students who entered the Student Diversity Program in 1994 and 1995 graduated at twice the rate of comparable students matched on sex, ethnicity, age, transfer status, entering GPA, and on semester they entered the university. The analysis of final GPA showed no statistically significant difference between the two groups, although the average final GPA in the Student Diversity Program appeared slightly higher than that of the comparison students. Further, GPAs from SDP students in the most recent semester did appear to be significantly higher. We attribute this improvement to our earlier intervention with new SDP students who were on academic probation.

\section{What Accounts for SDP Students Graduating at Twice the Rate of Other Students?}

Why did the SDP students graduate at a rate double that of comparison students? The most obvious explanation is that the Student Diversity Program is effective in accomplishing its stated goals. Other explanations include the possibility that other local support programs contributed to student success. Further analysis could examine the SDP students on a case-by-case basis to ascertain the extent to which they received support from sources outside the Student Diversity Program. In any case, the data provide support for the general pattern of findings that students who are more involved at their college or university are more likely to graduate (cf. Astin, 1993; Daly \& Breegle, 1989; Holmes et al., 2000, p. 54), and that a supportive environment that is culturally relevant fosters persistence (Glorio, 1997).

\section{Selection Bias?}

Another explanation is that despite the efforts noted above, the design failed to adequately match students. Although they were matched on the seven factors described above, they were not matched on motivation to do well in college. This is the "selection bias" explanation: a tendency for those more likely to do better in a program to participate in the program, as opposed to participating in the comparison group (cf. Campbell \& Stanley, 1963, pp. 12, 15). Volunteers would be more likely to enlist in the treatment program than in the control group, ensuring that more of any effect would occur in the treatment group than the control group, regardless of the efficacy of the treatment (treatment-selection invalidity). Thus, an alternate explanation for the higher graduation rate for SDP students than for comparison group students is that those students who already were more motivated to do well were both more likely to graduate, and to join a program to help them do so. This is not a criticism of the SDP program; any program is likely to receive participants in accord with participants' interest in that program. The only instance in which selection-treatment invalidity is not 
an alternate explanation for a treatment effect is when participants are randomly assigned to groups, or possibly when two equally desirable, but different programs are available. A method to rule out treatment-selection invalidity with respect to the Student Diversity Program (short of randomly assigning future participants) is to evaluate SDP students against students in a comparable volunteer program. In that case the selection bias would be removed to some extent, although that extent cannot be measured.

\section{Improvements for Future Research: Matching on Cumulative G.P.A.}

Matching on cumulative grade point average should be done at the point of entry to the SDP Program, not at the end of the first semester of university work. Specifically, a student who enters the university in Fall 1993 enters the SDP Program in Fall of 1995 might have a 2.05 when she finishes one semester of university and have a 1.85 two years later when she enters the SDP Program. In this research, we have matched on GPA at the end of the first semester (GPA = 2.05 in the example) not at the point of entry to the SDP Program (1.85 in the example). The difference may not be great in contrasting GPA at end of first semester and at entry to the SDP program. For now, we have made the assumption that GPA at end of first semester is not significantly different from GPA at entry to the SDP program. That assumption should be tested by tracking student GPA change over time, and replicating the study with GPA matching as outlined above. In an informal test of GPAs at end of first semester versus entry to the SDP program, we found little difference.

\section{Other Ways to Evaluate the SDP Program}

There are other ways to evaluate academic support programs; for example, the criteria for success could have been other than the criteria used in these studies: GPA, graduation rates, and academic standing. We could have examined positive attitudes towards learning, or other outcome measures. Another approach, as introduced above, is to select a different treatment group rather than a no-treatment group to serve as the comparison group. Instead of students not in the SDP, we could have selected students in a different academic support program, and then contrasted the relative effectiveness of the two programs by comparing them on final GPA and graduation rates, or on other outcome measures. A third approach would involve comparing SDP students to matched students at another university where there is no such support program, or where there is a different type of support program. This would allow matching of athletes with other athletes, unlike in the current study, in which all or nearly all the athletes were already in the "treatment" group. 


\section{ACKNOWLEDGMENTS}

We thank Dr. Cherine Trombley for data handling and calculations, and Farhan Abassi, Jeff Herzog, and Susan Kachner for extensive programming to provide extractions from the student records database. We also thank Carole Jones, Sabrina Sanders, Deborah Corey, and Jerry Moore for helpful comments.

\section{REFERENCES}

Astin, A. (1993). What matters in college: Four critical years revisited. San Francisco: Jossey-Bass.

Campbell, D. T., \& Stanley, J. C. (1963). Experimental and quasi-experimental designs for research. Chicago: Rand McNally.

Cook, T., \& Campbell, D. (1979). Quasi-experimentation: Design \& analysis issues for field settings. Chicago: Rand McNally.

Cozby, P. C. (1997). Methods in behavioral research. Mountain View, CA: Mayfield.

Daly, B., \& Breegle, G. (1989). Retention in higher education: A statewide perspective. Paper read at Association for Institutional Research, Baltimore. (From Higher Education Abstracts, 1989, 25(1)u, Abstract No. 0231-25).

Glorio, A. (1997). Chicana academic persistency: Creating a university-based community. Education and Urban Society, 30, 107-121.

Holmes, S., Ebbers, L., Robinson, D., \& Mugenda, A. (2000). Validating African American students at predominantly white institutions. Journal of College Student Retention, 2(1), 41-58.

Ottens, A., Johnson, I., \& Green, J. (1996). Summary and additional resources (promoting academic success for students of color). New Directions for Student Services, 74, 93-98.

Peltier, G., Laden, R., \& Matranga, M. (1999). Student persistence in college: A Review of the research. Journal of College Student Retention, 1(4), 357-375.

Reld, J. (1996). Black Ombudsman Program Model. In C. Ford (Ed.), Student Retention Models in Higher Education (pp. 193-200). Tallahassee: CNJ Associates.

Sedlacek, W. (1996). Employing noncognitive variables in admitting students of color. New Directions for Student Services, No. 74, pp. 79-84, cited in Leveling the Playing Field: Promoting Academic Success for Students of Color. San Francisco: Jossey-Bass.

Tracey, T., \& Sedlacek, W. (1987). Prediction of college graduation using noncognitive variables by race. Measurement and Evaluation in Counseling and Development, 19, $177-184$.

Direct reprint requests to:

John F. Reid, Jr.

California State University

PO Box 6830

Building UH 183

Fullerton, CA 92834-6830 